\title{
Radiation Therapy in Intracranial Ependymoma Revisited - A Single Institution Series of 21 Patients from South India
}

\author{
Pradeep Kumar K N ${ }^{1 *}$, Ashwini Lakshmaiah ${ }^{2}$ and Devika Sunil ${ }^{3}$ \\ ${ }^{1}$ Senior Resident, Department of Radiation Oncology, Kidwai Memorial Institute of Oncology, India \\ ${ }^{2}$ Assistant professor, Department of Radiation Oncology, Kidwai Memorial Institute of Oncology, India \\ ${ }^{3}$ Senior Resident, Department of Radiation Oncology, Yashoda Hospital, India
}

Submission: April 27, 2020; Published: May 05, 2020

*Corresponding author: Pradeep Kumar K N, Department of Radiation Oncology, Kidwai memorial institute of Oncology, Bengaluru, India

\begin{abstract}
Purpose: Ependymoma is a relatively rare glial tumor arising from the ependymal lining of the central nervous system. Multiple factors have been shown to influence the prognosis individually, in our study, we tried to analyze the outcome of patients with intracranial Grade II/III ependymoma who were treated with postoperative radiation therapy at our institute with respect to various risk factors including histological grade \& the extent of surgical resection.

Methods: We analyzed 21 patients with intracranial ependymoma [Grade II/III] who treated with post-operative radiation from June 2009 to August 2016 was done. The age of the patients ranged from 2 - 61 years [median-32 years], 10 patients were diagnosed with Grade II \& 11 patients had Grade III ependymoma according to WHO Grading System. All patients with [n=11;52.38\%] \& without [n=10; 47.61\%] operative residual disease as per MRI, were offered external beam radiation therapy with 45Gy to 60Gy [median dose-5040cGy], using 15 or $6 \mathrm{MV}$ photons beams. Median follow up period was 32 months [range, 5 months to 92 months].
\end{abstract}

Results: Eight out of 21 patients had tumor progression \& 5 among them had Grade II ependymoma. 7 patients succumbed to disease-related complications within 12 months of progression. The study showed that after a median follow up 20 months, patients who had incomplete resection progressed faster than those who had no post-operative residual disease [88.9\% versus 54.5\%; $\mathrm{p}=0.028$ ]. In terms of histology, PFS for Grade II \& Grade III were $71.6 \%$ \& $68.6 \%$, respectively, after a median follow up of 15 months. The cumulative overall survival at a median follow up of 32 months was $68.5 \%$ [61.4\% versus $78.8 \%$ in Grade II \& III, respectively] The overall survival rate, in patients with post-operative residue was $63.6 \% \& ; 87.5 \%$, in patients who had complete resection [p=0.116].

Conclusion: In this study, we conclude that extent of surgical resection is one of the most important prognostic factors in intracranial ependymoma. Grade of the tumor, which was thought to influence the PFS \& OS, did not show any significant difference with respect to progression as well as survival, which warrants molecular studies to detect ST-EPN-RELA and PF-EPN-A. We recommend more randomized clinical studies to look into the benefits of SRS either as an adjuvant choice of therapy in case of small volume tumors or as a boost following EBRT in large tumor volumes, especially in a residual disease status.

\section{Introduction}

Ependymoma is a relatively rare glial tumor arising from the ependymal lining of the central nervous system, accounting for $3-9 \%$ of intracranial tumors. About one third of the brain ependymoma arise supratentorially \& two thirds are of infratentorial origin. Ependymal tumors are categorized by World Health Organization [WHO] into Grade I - subependymoma \& myxopapillary ependymoma, Grade II - cellular, tancytic, papillary \& clear cell and Grade III-anaplastic type [1,2]. As these tumors are not common compared to other intracranial neoplasms, it has been difficult to standardize the optimal treatment. Current consensus is surgical resection with gross total resection (GTR) whenever feasible. Comprehensive review of literature has been done to evaluate the role of adjuvant radiation therapy in delaying the progression [3]. Ideally, an optimal paradigm of treatment for each patient should be defined based on the tumor features to prolong progression-free survival (PFS) and overall survival (OS). Multiple factors have been shown to influence the prognosis individually like the tumor grade [4-6], tumor size [7], duration of clinical history [8], preoperative neurological status [9], presence 


\section{Cancer Therapy \& Oncology International Journal}

of distant metastasis [10], adjuvant radiotherapy [7], and extent of resection which are the few factors studied

extensively. Among these, extent of surgical resection seems to be the most consistent variable in predicting improved OS and PFS [11,12], whereas others remain controversial. In this study, we review the survival rate, progression free survival interval, of Grade II \& Grade III intracranial ependymoma patients, who have received radiation therapy following surgical resection [GTR/ STR/biopsy] at our institution.

\section{Materials \& methods}

Twenty-one cases (Table 1) with intracranial ependymoma [Grade II/III], which were treated with post-operative radiation therapy from June 2009 to August 2016, were reviewed. The age of the patients ranged from 2 years to 61 years [median-32 years]; 9 out of 21 patients were of pediatric age group. The male to female ratio was $12: 9 ; 4$ patients had Karnofsky performance score [KPS] of $>80$. All the patients underwent Computed Tomography [CT], Magnetic resonance imaging [MRI] of the brain. Surgery was performed with the aim of gross total resection in all patients and the extent of surgical resection was categorized as complete or incomplete resection and included 10 (47.6\%) and 11 (52.3\%; 8-Grade II, 3-Grade III) patients, respectively. Histological examination revealed 10 patients had Grade

Table 1: Post-operative radiation therapy.

\begin{tabular}{|c|c|c|}
\hline & Grade II & Grade III \\
\hline $\mathrm{N}=21$ & 11 & 10 \\
\hline \multicolumn{3}{|l|}{ AGE: } \\
\hline$<18$ years & 2 & 6 \\
\hline >18 years & 9 & 4 \\
\hline Male: Female & $6: 5$ & $6: 4$ \\
\hline \multicolumn{3}{|l|}{$\begin{array}{l}\text { Karnofsky performance } \\
\text { score }\end{array}$} \\
\hline$<70$ & 6 & 6 \\
\hline $70-100$ & 5 & 4 \\
\hline $\begin{array}{c}\text { Post-operative residue } \\
\text { present }\end{array}$ & 8 & 4 \\
\hline \multicolumn{3}{|l|}{ Radiation dose } \\
\hline$<54 \mathrm{~Gy}$ & 10 & 3 \\
\hline$>54 \mathrm{~Gy}$ & 1 & 7 \\
\hline Progression [n] & 5 & 3 \\
\hline Mortality [n] & 4 & 3 \\
\hline
\end{tabular}

AI \& 11 patients had Grade III ependymoma according to WHO Grading System (2007). CSF analysis was done in patients who were diagnosed with Grade III ependymoma. Two patients had cerebrospinal fluid (CSF) positive for malignancy. Considering the grade of tumor \& extent of resection, all patients were planned for external beam radiation therapy. Clinical target volume (CTV) was defined as $1.5 \mathrm{~cm}$ extension from the tumor bed and a planning target volume (PTV) margin of $5 \mathrm{~mm}$ from the CTV, was added. Radiation therapy with a median dose of 5040cGy in 28 fractions [range, 4500cGy to 6000cGy]; and cranio-spinal irradiation (CSI) was performed for 2 patients with CSF seeding followed by boost dose to the tumor bed. All the patients were treated with external beam radiation therapy using 15 or $6 \mathrm{MV}$ photons beam.

During radiation therapy, patients were assessed once a week for acute toxicities. After completion of treatment, patients were followed up three monthlies for the first 2 years and every 6-12 monthly thereafter and were evaluated with clinical examination and MRI; and tissue confirmation was done in cases with suspected progression. Median follow up period was 32 months [range, 5 92 months]. Duration for endpoint was calculated from the date of completion of radiation therapy. Progression-free survival (PFS) and overall survival (OS) were estimated with the Kaplan-Meier method using the SPSS software Version 2.0. The impact of clinical and therapeutic variables on survival was evaluated by comparing entire OS curves using the log-rank test. Probability (p) values < 0.05 were considered significant.

\section{Results}

Eight out of 21 patients had tumor progression and 5 of them were in Grade II group. One among the 8 patients who had anaplastic variant had change in grade of the tumor to Glioblastoma Multiforme [WHO Grade IV] which was histologically confirmed. Three out of 8 patients were started on steroids, 2 of them were started on chemotherapy with Temozolamide \& rest of the cases was treated symptomatically. Seven patients succumbed to death within 12 months of progression. Two patients had aspiration pneumonia; 1 patient had sepsis \& rest of them had disease related complications. One patient who had disease progression is currently alive \& receiving chemotherapy with Temozolamide \& has KPS of 70 (Figures $1 \& 2$ ).

Considering the 11 [52.38\%] patients with residual disease post-surgery \& 10 [47.61\%] patients who had complete resection of the tumor, the progression free rate after a median follow up of 20 months was $88.9 \%$ \& $45.5 \%$, respectively, which was statistically significant $[\mathrm{p}=0.028]$; while the overall progression free rate was $64.6 \%$ at 20 months. In terms of histology, the overall progression free rate for Grade II \& Grade III groups was $54.5 \%$ \& $70.0 \%$, respectively. The cumulative overall survival at a median follow up of 32 months was $68.5 \%$ [61.4\% vs. $78.8 \%$ in Grade II vs. Grade III, respectively]. The overall survival rate at 32 months with post-operative residual disease was 54.5\% \& 87.5\% in complete resection arm [p=0.116] (Figures 4-6). 


\section{Cancer Therapy \& Oncology International Journal}

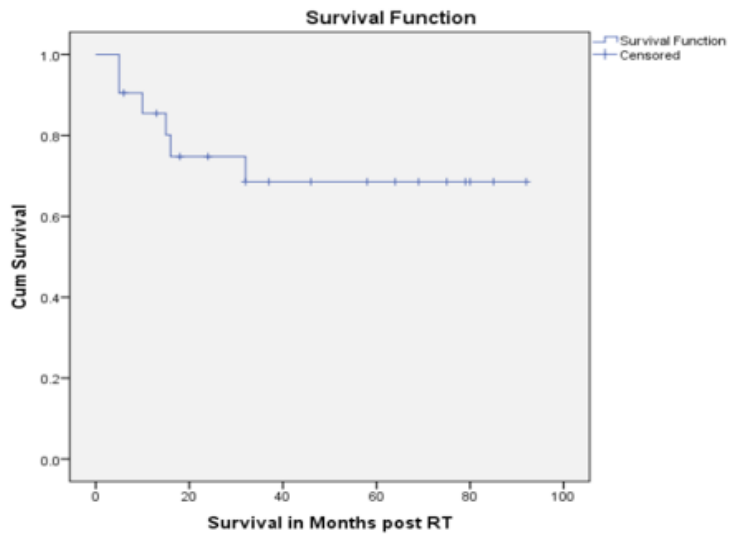

Figure 1: OS

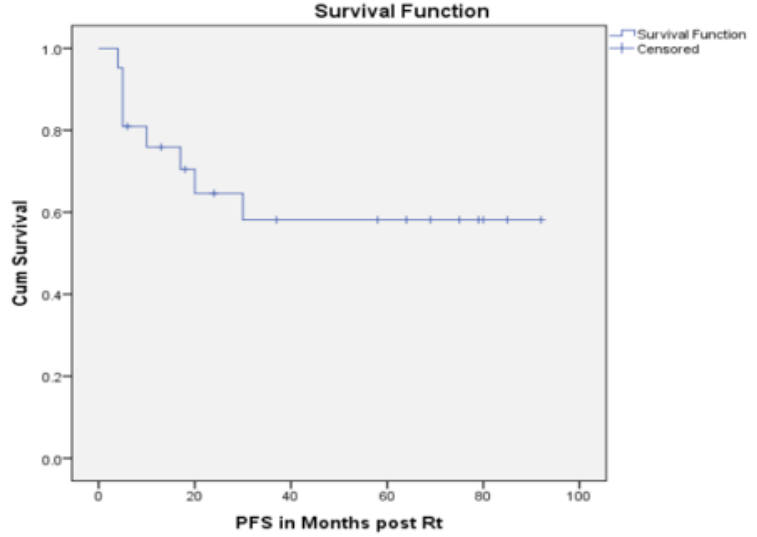

Figure 2: PFS; $\mathrm{N}=21$; No of events=8.

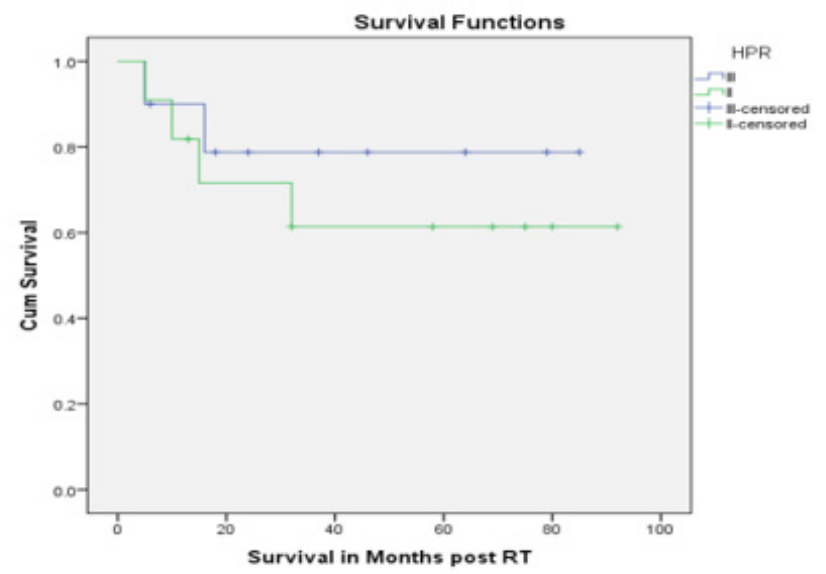

Figure 3: Survival in Months post RT. 


\section{Cancer Therapy \& Oncology International Journal}

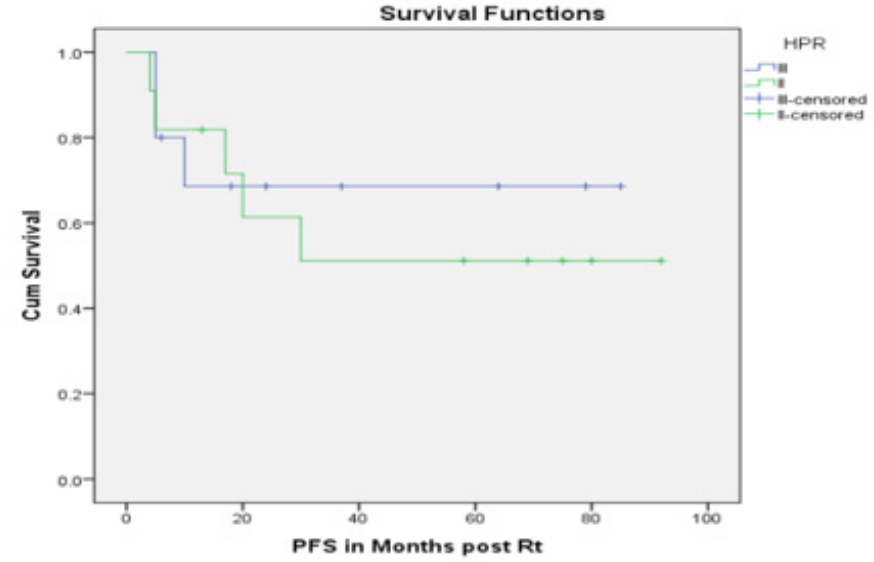

Figure 4: PFS in Months post Rt.

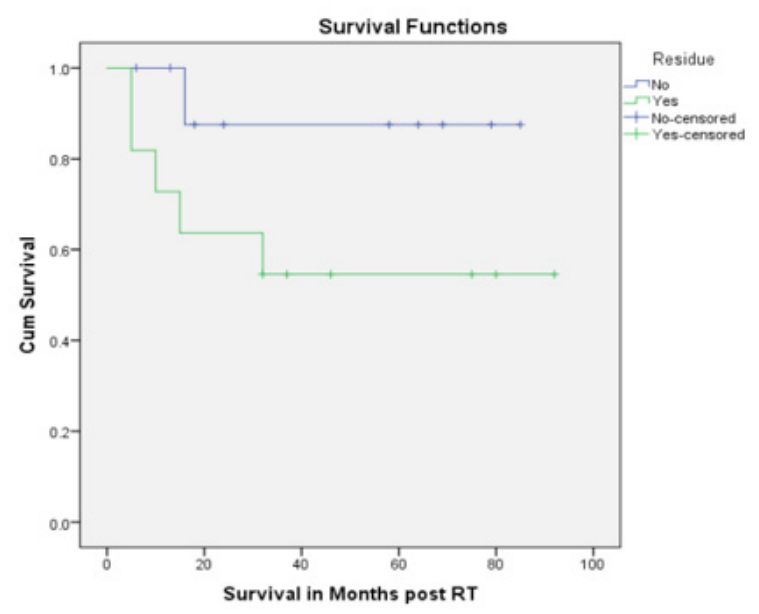

Figure 5: Survival in Months post RT.

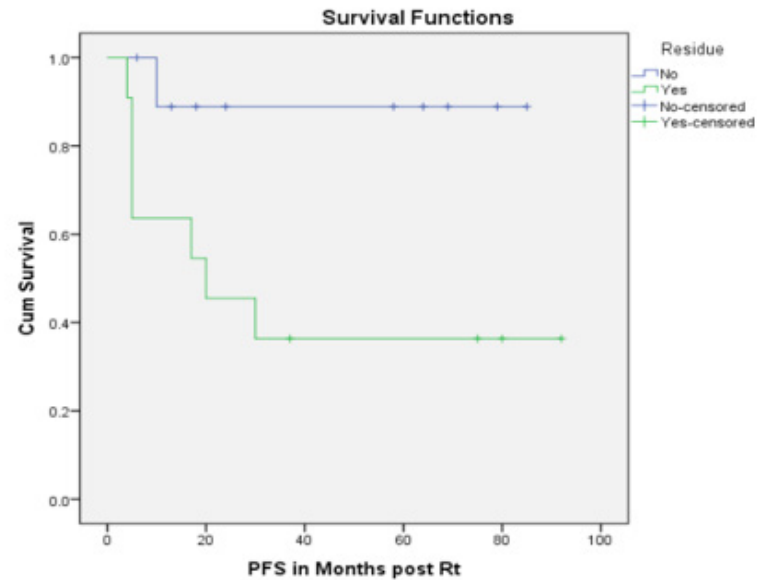

Figure 6: PFS in Months post Rt. 


\section{Cancer Therapy \& Oncology International Journal}

\section{Discussion}

In our current study, we present the survival rate \& progression free rate of patients with Grade II/III intracranial ependymoma who received post-operative adjuvant radiation therapy which is $66.66 \%$ \& $61.9 \%$, respectively, after a median follow up of 32 months. The incidence of Grade III ependymoma was higher in pediatric age group than in adults (Table 1). On univariate analysis, the OS for Grade II ependymoma was $71.4 \%$ \& for Grade III was 70\%. The PFS was $54.4 \%$ \& $70 \%$ which could be due to a greater number of incomplete resections in Grade II group (8) compared to Grade III category (3). Another possible reason is that the biological behavior of Grade II is like Grade III tumor which warrants molecular classification as described in WHO classification $(2016)[13,14]$ which classify ependymoma to either Grade I or Grade III and Grade II has been removed.

Another important prognostic factor, in terms of progression and survival, which is extent of surgical resection, has been justified in this study. The overall survival in patients with \& without residual disease was $45.46 \%$ versus $90 \%$ \& progression free survival was $36.4 \%$ versus $90 \%$ [ $p=0.028]$, respectively, which was statistically significant. This shows that the extent of resection and residual disease prior to radiation therapy is an important prognostic factor. Similar result was seen in another study where gross total resection alone was an independent prognostic factor, regardless of the histological grade [15].

Subgroup analysis based on age group ( $<18$ or $\geq 18 y e a r s$ ) did not show any significant difference with respect to progression or survival. As most of the tumor recurrences were in the irradiated area, especially in case of post-operative residual sites, boost with stereotactic radiosurgery [SRS] could be considered as next line treatment. A retrospective analysis of 45 patients with intracranial ependymoma, out of which 37 patients had post-operative radiation failure and 14 patients had progressive disease after chemotherapy and radiation. Eight patients among these received SRS boost after initial radiation or radiation plus chemotherapy. These patients were treated with SRS with a median marginal dose of $15 \mathrm{~Gy}$. The overall survival after radiosurgery was 65,41 , and $38 \%$ at 1,3 and 5 years, respectively. The progression-free survival after SRS at 1, 3 and 5 years, respectively were 82\%, 52\% and $52 \%$ for all grades of ependymoma. Histologic grade of tumor was not a statistically significant factor for better PFS ( $p=0.725)$. Factors associated with an improved progression-free survival included smaller tumor volume and homogeneous tumor contrast enhancement. Adjuvant SRS provides another management option for patients with residual or recurrent ependymoma. Predictors of response include older age, smaller treatment volume, lower grade, and homogeneous contrast enhancement.

There are few drawbacks in this study among which the main limitation is the relatively small number of cases, which limits the statistical power of analyses. Genetic and molecular grouping test for ST-EPN-RELA and PF-EPN-A, were not done which are recently found to be of superior prognostic value [16]

\section{Conclusion}

In this study, we conclude that the extent of surgical resection is one of the most important prognostic factors in intracranial ependymoma. Grade of the tumor [II/III] may not influence the progression or survival rates significantly. We recommend more randomized clinical studies to investigate the benefits of SRS either as an adjuvant choice of therapy in case of small volume tumors or as a boost following EBRT in large tumor volumes, especially in a residual disease status.

\section{Acknowledgement}

The authors have no conflicts of interest.

\section{References}

1. Gurney JG, Smith MA, Bunin GR, Ries LA, Smith MA, et al. (1999) Cancer incidence and survival among children and adolescents: United States SEER program 1975- 995. MD: National Cancer Institute, Bethesda, USA, p. 51-64.

2. Louis DN, Ohgaki H, Wiestler OD, Cavenee WK, Burger PC, et al. (2007) The 2007 WHO classification of tumours of the central nervous system. Acta Neuropathol 114(2): 97-109.

3. Oh MC, Ivan ME, Sun MZ, Kaur G, Safaee M, et al. (2013) Adjuvant radiotherapy delays recurrence following subtotal resection of spinal cord ependymomas. Neuro-Oncology 15(2): 208-215.

4. Waldron JN, Laperriere NJ, Jaakkimainen L, Simpson WJ, Payne D, et al. (1993) Spinal cord ependymomas: a retrospective analysis of 59 cases. Int J Radiat Oncol Biol Phys 27(2): 223-229.

5. Mork SJ, Loken AC (1977) Ependymoma: a follow-up study of 101 cases. Cancer 40(2): 907-915.

6. Armstrong TS, Vera-Bolanos E, Bekele BN, Aldape K, Gilbert MR (2010) Adult ependymal tumors: prognosis and the M. D. Anderson Cancer Center experience. Neuro-Oncology 12(8): 862-870.

7. Wahab SH, Simpson JR, Michalski JM, Mansur DB (2007) Long term outcome with post-operative radiation therapy for spinal canal ependymoma. J Neurooncol 83(1): 85-89.

8. Cervoni L, Celli P, Fortuna A, Cantore G (1994) Recurrence of spinal ependymoma. Risk factors and long-term survival. Spine (Phila Pa 1976) 19(24): 2838-2841.

9. Hanbali F, Fourney DR, Marmor E, Suki D, Rhines LD, et al. (2002) Spinal cord ependymoma: radical surgical resection and outcome. Neurosurgery 51(5): 1162-1172; discussion 1172-1174.

10. Marks JE, Adler SJ (1982) A comparative study of ependymomas by site of origin. Int J Radiat Oncol Biol Phys 8(1): 37-43.

11. Sonneland PR, Scheithauer BW, Onofrio BM (1985) Myxopapillary ependymoma. A clinicopathologic and immunocytochemical study of 77 cases. Cancer 56(4): 883-893.

12. Asazuma T, Toyama Y, Suzuki N, Fujimura Y, Hirabayshi K (1999) Ependymomas of the spinal cord and cauda equina: An analysis of 26 cases and a review of the literature. Spinal Cord 37(11): 753-759.

13. Hideyuki Kano, Niranjan A, Kondziolka D, Flickinger JC, Dade Lunsford, et al. (2010) Stereotactic Radiosurgery for Intracranial Ependymomas. Tumors of Central nervous system, Volume 4 of the series Tumors of Central Nervous System pp. 263-271. 


\section{Cancer Therapy \& Oncology International Journal}

14. Louis DN, Perry A, Reifenberger G, von Deimling A, Figarella-Branger D, et al. (2016) The 2016 World Health Or-ganization Classification of Tumors of the Central Nervous System: a summary. Acta Neuropathol 131(6): 803-820.

15. Gajjar A, Packer RJ, Foreman NK, Cohen K, Haas-Kogan D, et al. (2013) Children's Oncology Group's 2013 blueprint for research: central nervous system tumors. Pediatr Blood Cancer 60: 1022-1026.
16. Pajtler KW, Witt H, Sill M, Jones DT, Hovestadt V, et al. (2015) Molecular classification of ependymal tumors across all CNS compartments, histopathological grades, and age groups. Cancer Cell 27(5): 728-743.

\section{Your next submission with Juniper Publishers will reach you the below assets}

- Quality Editorial service

- Swift Peer Review

- Reprints availability

- E-prints Service

- Manuscript Podcast for convenient understanding

- Global attainment for your research

- Manuscript accessibility in different formats

( Pdf, E-pub, Full Text, Audio)

- Unceasing customer service

Track the below URL for one-step submission https://juniperpublishers.com/online-submission.php 